\title{
The relation between echocardiographic epicardial fat thickness and mitral annular calcification
}

\author{
Serdar Guler, Ercan Varol
}

Department of Cardiology, Suleyman Demirel University, Medical School, Isparta, Turkey.

\begin{abstract}
Background: Mitral annular calcification (MAC) is associated with several cardiovascular disorders including coronary artery disease (CAD), atrial fibrillation, heart failure, ischemic stroke and increased mortality. Epicardial fat thickness (EFT) has strong correlation with obesity, CAD, insulin resistance, metabolic syndrome, hypertension, diabetes mellitus, and atherosclerosis. There are strong similarities between EFT and MAC from the aspect of risk factors and pathogenesis.
\end{abstract}

Objective: In this study we aimed to investigate the EFT in patients with MAC.

Methods: The study group consisted of 78 patients with MAC. An age, gender and body mass index matched control group consisted of 47 subjects who admitted to echocardiography laboratory due to suspicion of organic heart disease and eventually found to be free of MAC. We measured EFT in patients with MAC and control subjects.

Results: EFT was significantly higher in patients with MAC than in control subjects (5.7 \pm 0.9 vs. $4.4 \pm 0.6$ mm respectively; $\mathrm{P}<$ 0.001). Correlation analysis indicated that EFT was positively correlated with presence of MAC $(\mathrm{p}<0.001, \mathrm{r}=0.597)$.

Conclusion: We showed that EFT was significantly elevated in patients with MAC and it was positively correlated with MAC.

Keywords: mitral annular calcification, epicardial fat thickness, cardiovascular risk.

DOI: https://dx.doi.org/10.4314/ahs.v19i1.41

Cite as: Guler S, Varol E. The relation between echocardiographic epicardial fat thickness and mitral annular calcification. Afri Health Sci. 2019;19(1). 1657-1664. https://dx.doi.org/10.4314/abs. v19i1.41

\section{Introduction}

Mitral annular calcification (MAC) is characterized by calcium and lipid deposition on mitral valve ring. ${ }^{1}$ It has been associated with coronary artery disease (CAD), atrial fibrillation, heart failure, ischemic stroke and increased mortality. ${ }^{1-5}$ Risk factors for atherosclerotic CAD such as age, hypertension, diabetes mellitus and obesity are also risk factors for MAC. ${ }^{1} \mathrm{MAC}$ and atherosclerosis share the similar clinical risk factors and the presence of MAC may reflect the intensity and duration of exposure to the risk factors over time. ${ }^{1}$ However exact mechanism of association between two entity is not purely clear.

\section{Corresponding author: \\ Ercan Varol, \\ Suleyman Demirel University, \\ Medical School, Isparta, TURKEY \\ Telephone: +90 5323468258, \\ Fax: +90 2462324510 \\ Email: drercanvarol@yahoo.com}

Visceral fat tissue is an important predictor of cardio-metabolic diseases. Epicardial fat is located between the myocardium and visceral pericardium. Echocardiographically, it is identified as the relatively echo-free space between the outer wall of the myocardium and the visceral layer of pericardium. ${ }^{6}$ Epicardial fat is considered an important cardiovascular risk predictor, in view of producing and releasing several adipo-cytokines. ${ }^{7}$ Epicardial fat thickness (EFT) has strong correlation with obesity, impaired fasting glucose, insulin resistance, metabolic syndrome, hypertension, diabetes mellitus, and atherosclerosis. ${ }^{6-9}$

So there are similarities between EFT and MAC from the aspect of risk factors and their consequences. In this study, we aimed to investigate the EFT in patients with MAC to determine any relation between EFT and MAC.

\section{Patient and methods}

The study group consisted of 78 consecutive patients with MAC (41 females, 37 males, mean age 71.9 \pm 6.9 years). The study group were prospectively selected from the patients who admitted to Suleyman Demirel Univer-

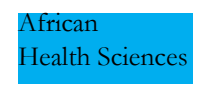

(C) 2019 Guler et al. Licensee African Health Sciences. This is an Open Access article distributed under the terms of the Creative commons Attribution License (https://creativecommons.org/licenses/BY/4.0), which permits unrestricted use, distribution, and reproduction in any medium, provided the original work is properly cited. 
sity Hospital, Cardiology out-patient clinic and echocardiography laboratory due to suspicion of heart disease between June 2014 and May 2015. The 47 control subjects (23 females, 24 males, mean age 69.7 \pm 4.7 years) were selected from peoples who were admitted to our outpatient clinic and echocardiography laboratory due to suspicion of heart disease at the same period and their echocardiographic examinations showed normal cardiac findings. All patients and control subjects underwent medical history, physical examination, anthropometric measurements, electrocardiogram, and echocardiographic evaluation. Patients having coronary angiogram with $>\% 50$ coronary lesion, coronary bypass surgery and percutaneous coronary intervention were regarded as having coronary artery disease. In other patients, there was no angina or equivalent symptoms. The study was approved by the institutional ethics committee and all patients gave their informed consent. Exclusion criteria were pericardial effusion, poor echocardiographic window, heart failure $(\mathrm{EF}<\% 50)$, history of chronic renal and liver disease, moderate to severe mitral and aortic regurgitation, moderate to severe mitral and aortic stenosis, malignancy, systemic or pulmonary embolism, chronic hematological diseases, acute or chronic inflammatory disease, autoimmune disease, hyperparathyroidism, hypercalcemia, hyperphosphatemia and a prosthetic valve.

\section{Echocardiography}

The M-mode, two-dimensional, and Doppler echocardiographic examinations were obtained by using GE VingMed System FiVe (Norway) to asses left atrial (LA) diameter, interventricular septum (IVS) thickness, left ventricular posterior wall (LWPW) thickness, left ventricular end diastolic diameter (LVEDD), left ventricular end systolic diameter (LVESD), left ventricular ejection fraction (EF), isovolumic relaxation time (IVRT), deceleration time (DT), myocardial performance index (MPI) and MAC. Left atrial and ventricular dimensions and left ventricular EF were measured by M-mode echocardiography in the parasternal long axis view by using the American Echocardiography Society M-mode technique. ${ }^{10} \mathrm{EF}$ was measured with $\mathrm{M}$ mode by the Teicholz method. MAC was defined as an intense echocardiography producing structure with highly reflective characteristics that was located at the junction of the atrioventricular groove and the posterior or anterior mitral leaflet on the parasternal long-axis, apical 4-chamber or 2-chamber, or parasternal short-axis view. ${ }^{11}$ The presence of mitral and aortic insufficiency was evaluated by Doppler color flow mapping. EFT was identified echocardiographically as the echofree space between the outer wall of the myocardium and the visceral layer of pericardium. EFT was measured at the point on the free wall of the right ventricle along the midline of the ultrasound beam, perpendicular to the aortic annulus at the end of systole (Fig 1). ${ }^{8}$ As Iacobellis et al. suggested, epicardial fat is best measured at end-systole, because it is compressed during diastole. ${ }^{8}$ The average value of three cardiac cycles was determined as epicardial fat thickness.

\section{Blood sampling}

Blood samples were drawn from the antecubital vein by careful venipuncture in a $21 \mathrm{G}$ sterile syringe without stasis at 08.00-10.00 AM after a fasting period of $12 \mathrm{~h}$. Glucose, creatinine, and lipid profiles were determined by standard methods. Hemogram parameters were measured in a blood sample collected in dipotassium EDTA tubes (Vacuette). An automatic blood counter (Beckman-Coulter Co, Miami, FL, USA) was used for whole blood counts.

\section{Statistical analysis}

Data were analyzed with the SPSS software version 15.0 for Windows. Continuous variables from the study groups were reported as mean \pm standard deviation, categorical variables as percentages. To compare continuous variables, the Student t-test was used. Categorical variables were compared with the chi-squared test. The correlations between MAC, EFT and other clinical, laboratory and echocardiographic parameters were performed with Pearson and Spearman correlation analysis where appropriate. A p value $<0.05$ was considered statistically significant.

\section{Results}

Baseline clinical features of the study and control groups were summarized in Table 1. There was no statistically significant differences between two groups with respect to age, gender, body mass index and other clinical parameters. There was $6(7.7 \%)$ atrial fibrillation in patients with $\mathrm{MAC}$, and there was no patient with atrial fibrillation in control group. 
Table 1. Baseline clinical features of the study and control groups

\begin{tabular}{|c|c|c|c|}
\hline & $\begin{array}{l}\text { Controls } \\
(n=47) \\
\end{array}$ & $\begin{array}{l}\text { MAC } \\
(n=78) \\
\end{array}$ & $P$ value \\
\hline Age (years) & $69.7 \pm 4.7$ & $71.9 \pm 6.9$ & 0.06 \\
\hline $\operatorname{Sex}(M / F)$ & $24 / 23$ & $37 / 41$ & 0.69 \\
\hline $\begin{array}{l}\text { Waist } \\
\text { circumferenca } \\
(\mathrm{cm})\end{array}$ & $98.4 \pm 13.0$ & $102.0 \pm 11.3$ & 0.11 \\
\hline $\operatorname{BMI}\left(\mathrm{kg} / \mathrm{m}^{2}\right)$ & $29.6 \pm 5.4$ & $31.3 \pm 7.6$ & 0.18 \\
\hline CAD n $(\%)$ & $6(12.7)$ & $20(25.6)$ & 0.08 \\
\hline Smoking, n (\%) & $5(10.6)$ & $5(6.4)$ & 0.39 \\
\hline $\begin{array}{l}\text { Family history, } \mathrm{n} \\
(\%)\end{array}$ & $2(4.2)$ & $5(6.4)$ & 0.61 \\
\hline $\begin{array}{ll}\begin{array}{l}\text { Heart } \\
\text { (beat/min) }\end{array} & \text { rate } \\
\end{array}$ & $69.2 \pm 12.8$ & $72.0 \pm 13.5$ & 0.25 \\
\hline SBP (mmHg) & $121.2 \pm 18.6$ & $122.8 \pm 18.1$ & 0.63 \\
\hline DBP (mmHg) & $75.1 \pm 9.3$ & $77.5 \pm 11.1$ & 0.20 \\
\hline $\mathrm{AF}, \mathrm{n}(\%)$ & $0(0,0)$ & $6(7.7)$ & 0.05 \\
\hline ASA, n (\%) & $15(31.9)$ & $36(46.1)$ & 0.11 \\
\hline Clopidogrel, n (\%) & $4(8.5)$ & $12(15.3)$ & 0.26 \\
\hline OA/NOA, n(\%) & $0(0.0)$ & $4(5.1)$ & 0.12 \\
\hline Statin, n (\%) & $10(21.3)$ & $22(28.2)$ & 0.39 \\
\hline ACEi, n (\%) & $10(21.3)$ & $22(28.2)$ & 0.39 \\
\hline ARB, n (\%) & $9(19.1)$ & $22(28.2)$ & 0.26 \\
\hline $\mathrm{CCB}, \mathrm{n}(\%)$ & $2(4.2)$ & $11(14.1)$ & 0.08 \\
\hline B Blocker, n (\%) & $11(23.4)$ & $37(47.4)$ & 0.03* \\
\hline Diuretic, n (\%) & $9(19.1)$ & $32(41.0)$ & $0.01 *$ \\
\hline
\end{tabular}

MAC: mitral annular calcification, $\mathrm{M} / \mathrm{F}$ : male/female, BMI: body mass index, CAD: coronary artery disease, SBP: systolic blood pressure, DBP: diastolic blood pressure, AF: atrial fibrillation, OA: oral anticoagulan, NOA: new oral anticoagulan, ACEi: angiotensin converting enzyme inhibitor, ARB: angiotensin receptor blocker, CCB: calcium channel blocker 
However this difference didn't reach the statistically significant level $(\mathrm{p}=0.05)$. Only B blocker and diuretic usage was significantly higher in the MAC group. The labora- tory findings of the study and control groups were summarized in Table 2. There was no statistically significant difference between two groups.

Table 2. The laboratory findings of the study and control groups

\begin{tabular}{|l|l|l|l|}
\hline & $\begin{array}{l}\text { Controls } \\
(\mathrm{n}=47)\end{array}$ & $\begin{array}{l}\text { MAC } \\
(\mathrm{n}=78)\end{array}$ & P value \\
\hline Glucose $(\mathrm{mg} / \mathrm{dl})$ & $124.9 \pm 67.2$ & $128.4 \pm 62.0$ & 0.72 \\
\hline Creatinine (mg/dl) & $0.9 \pm 0.2$ & $0.9 \pm 0.2$ & 0.21 \\
\hline Total Cholesterol (mg/dl) & $180.4 \pm 52.6$ & $190.8 \pm 48.1$ & 0.26 \\
\hline Triglyceride (mg/dl) & $140.5 \pm 105.8$ & $154.8 \pm 73.9$ & 0.37 \\
\hline LDL- Cholesterol (mg/dl) & $108.6 \pm 38.0$ & $113.6 \pm 39.0$ & 0.48 \\
\hline HDL- Cholesterol (mg/dl) & $47.7 \pm 15.1$ & $45.8 \pm 11.5$ & 0.43 \\
\hline AST (mg/dl) & $23.5 \pm 7.7$ & $22.1 \pm 8.5$ & 0.35 \\
\hline ALT (mg/dl) & $20.1 \pm 14.6$ & $18.8 \pm 13.1$ & 0.59 \\
\hline Na (mmol/L) & $138.6 \pm 2.3$ & $136.8 \pm 14.8$ & 0.40 \\
\hline K (mmol/L) & $4.3 \pm 0.4$ & $4.4 \pm 0.4$ & 0.22 \\
\hline Ca (mg/dL) & $9.1 \pm 0.5$ & $9.2 \pm 0.6$ & 0.54 \\
\hline P (mg/dL) & $3.2 \pm 0.7$ & $3.3 \pm 0.7$ & 0.42 \\
\hline ALP (U/L) & $82.9 \pm 26.0$ & $85.6 \pm 49.3$ & 0,72 \\
\hline Hemoglobin (g/dl) & $13.4 \pm 1.9$ & $13.1 \pm 1.6$ & 0.37 \\
\hline WBC ( $\left.\times 10^{9} / \mathrm{L}\right)$ & $7.6 \pm 2.0$ & $7.7 \pm 2.7$ & 0.79 \\
\hline Platelet count $\left(\times 10^{9}\right)$ & $248.5 \pm 90.0$ & $243.8 \pm 65.0$ & 0.73 \\
\hline MPV (fl) & $8.6 \pm 1.3$ & $8.4 \pm 1.0$ & 0.42 \\
\hline & & & \\
\hline
\end{tabular}

LDL-cholesterol: low density lipoprotein cholesterol, HDL-cholesterol: high density lipoprotein cholesterol, AST: aspartate aminotransferase ALT: alanine aminotransferase, ALP: aspartate aminotransferase, WBC: white blood cell MPV: mean platelet volume. $\mathrm{P}$ value is for comparison between control and study population. 
Echocardiographic findings of the study and control groups were summarized in Table 3. LA diameter was significantly higher in patients with MAC than in control subjects $(37.2 \pm 4.4$ vs. $35.5 \pm 4.0 \mathrm{~mm}$ respectively; $\mathrm{P}=0.03)$. IVS thickness was significantly higher in $\mathrm{pa}-$ tients with MAC than in control subjects $(11.3 \pm 1.5$ vs. $10.7 \pm 1.4 \mathrm{~mm}$ respectively; $\mathrm{P}=0.03)$. LVEDD was sig- nificantly higher in patients with MAC than in control subjects $(46.1 \pm 3.3$ vs. $44.9 \pm 2.8 \mathrm{~mm}$ respectively; $\mathrm{P}=$ 0.04). LVESD was significantly higher in patients with MAC than in control subjects $(28.9 \pm 3.5$ vs. $27.2 \pm 2.6 \mathrm{~mm}$ respectively; $\mathrm{P}=0.005)$. EFT was significantly higher in patients with MAC than in control subjects $(5.7 \pm 0.9$ vs. $4.4 \pm 0.6 \mathrm{~mm}$ respectively; $\mathrm{P}<0.001)$.

Table 3. The echocardiographic findings of the study and control groups.

\begin{tabular}{|l|l|l|l|}
\hline & $\begin{array}{l}\text { Controls } \\
(\mathrm{n}=47)\end{array}$ & $\begin{array}{l}\text { MAC } \\
(\mathrm{n}=78)\end{array}$ & P value \\
\hline Aort $(\mathrm{mm})$ & $25.3 \pm 2.5$ & $25.9 \pm 2.4$ & \multicolumn{1}{|c|}{0.14} \\
\hline LA $(\mathrm{mm})$ & $35.5 \pm 4.0$ & $37.2 \pm 4.4$ & $0.03^{*}$ \\
\hline IVS $(\mathrm{mm})$ & $10.7 \pm 1.4$ & $11.3 \pm 1.5$ & $0.03^{*}$ \\
\hline LVPW $(\mathrm{mm})$ & $9.9 \pm 0.9$ & $10.0 \pm 0.8$ & \multicolumn{1}{c|}{0.29} \\
\hline LVESD $(\mathrm{mm})$ & $27.2 \pm 2.6$ & $28.9 \pm 3.5$ & $0.005^{*}$ \\
\hline LVEDD $(\mathrm{mm})$ & $44.9 \pm 2.8$ & $46.1 \pm 3.3$ & $0.04^{*}$ \\
\hline SPAP $(\mathrm{mmHg})$ & $25.5 \pm 10.8$ & $28.7 \pm 9.6$ & 0.08 \\
\hline EF $(\%)$ & $60.0 \pm 2.3$ & $58.8 \pm 4.2$ & 0.07 \\
\hline EFT $(\mathrm{mm})$ & $4.4 \pm 0.6$ & $5.7 \pm 0.9$ & $\mathrm{P}<0.001$ \\
\hline E/A & $0.7 \pm 0.1$ & $0.8 \pm 0.4$ & 0.13 \\
\hline IVRT $(\mathrm{ms})$ & $82.6 \pm 19.0$ & $84.0 \pm 13.2$ & 0.64 \\
\hline DT $(\mathrm{ms})$ & $192.3 \pm 40.4$ & $190.5 \pm 34.0$ & 0.79 \\
\hline MPI & $0.38 \pm 0.05$ & $0.41 \pm 0.06$ & $0.008^{*}$ \\
\hline
\end{tabular}

MAC: mitral annular calcification, LA: left atrium, IVS: Interventricular septum, LVPW: Left ventricular posterior wall, LVEDD: Left ventricular end diastolic diameter, LVESD: Left ventricular end systolic diameter, SPAP: systolic pulmonary artery pressure, EF: ejection fraction, EFT: epicardial fat thickness, IVRT: isovolumic relaxation time, DT: deceleration time, MPI: myocardial performance index, $\mathrm{P}$ value is for comparison between controls and overall study subjects $* p<0.05$ (control subjects versus patients with MAC)

Correlation analysis between EFT and other clinical and echocardiographic parameters were shown in Table 4. EFT was positively correlated with presence of MAC ( $\mathrm{r}=0.597, \mathrm{p}<0.001)$. The EFT was positively correlated with age $(\mathrm{r}=0.390, \mathrm{p}<0,001)$, alkalen phosfatase ( $\mathrm{r}=0.203, \mathrm{p}=0.02)$, LA $(\mathrm{r}=0.193, \mathrm{p}=0.03)$, IVS $(\mathrm{r}=0.260$, $\mathrm{p}=0.003)$, LVESD $(\mathrm{r}=0.180, \mathrm{p}=0.04)$, and waist circumference $(\mathrm{r}=0.237, \mathrm{p}=0.008)$. Negative correlation was found between EFT and alanine aminotransferase $(\mathrm{r}=-$ $0.183, \mathrm{p}=0.04)$ and $\mathrm{EF}(\mathrm{r}=-0.180, \mathrm{p}=0.04)$. 
Table 4. The clinical and echocardiographical parameters showing the significant correlation with EFT.

\begin{tabular}{|l|l|l|}
\hline & $\mathrm{r}$ & $\mathrm{p}$ \\
\hline Age & 0.390 & $<0.001^{*}$ \\
\hline ALT & -0.183 & $0.04^{*}$ \\
\hline ALP & 0.203 & $0.02^{*}$ \\
\hline LA & 0.193 & $0.03^{*}$ \\
\hline IVS & 0.260 & $0.03^{*}$ \\
\hline LVESD & 0.180 & $0.04^{*}$ \\
\hline EF & -0.180 & $0.04^{*}$ \\
\hline MPI & 0.212 & $0.02^{*}$ \\
\hline Waist circumference & 0.237 & $0.008^{*}$ \\
\hline
\end{tabular}

EFT: epicardial fat thickness, ALT: alanine aminotransferase, ALP: aspartate aminotransferase, LA: left atrium, IVS: interventricular septum, LVESD: Left ventricular end systolic diameter, EF: ejection fraction, MPI: myocardial performance index

\section{Discussion}

In the present study, we examined EFT in patients with MAC. We found that EFT was significantly higher in patients with MAC than in control subjects and EFT was positively correlated with presence of MAC.

MAC is associated with several cardiovascular disorders including CAD, atherosclerosis, heart failure, stroke and atrial fibrillation. ${ }^{1-5}$ Risk factors for atherosclerotic CAD such as age, hypertension, diabetes mellitus and obesity are also risk factors for MAC. ${ }^{12}$

Regional distribution of adipose tissue, rather than general obesity, has increasingly gained attention as a marker for cardiovascular disease. ${ }^{13}$ Epicardial adipose tissue is a true visceral fat tissue, deposited around the heart on the free wall of the right ventricle, left ventricular apex and atrium. Previous studies showed that epicardial adipose tissue was associated with abdominal fat. ${ }^{14}$ Epicardial fat has been suggested to influence CADdevelopment due to its proximity to the coronary arteries and absence of a physical barrier between it and the coronary artery walls and myocardium.

The mechanism of the relationship between epicardial fat and MAC are not fully established.
Two potential mechanisms can be proposed for this association: first, epicardial adipose tissue is a component of visceral adiposity and is related to metabolic syndrome and cardiovascular risk factors, secondly, epicardial adipose tissue acts as a paracrine and endocrine organ ${ }^{6-8}$ It can secrete numerous bioactive molecules (adipokines, such as adiponectin, resistin) and inflammatory cytokines (tumor necrosis factor-a, monocyte chemoattractant protein-1, interlukin-6, nerve growth factor, resistin, visfatin, omentin, leptin, plasminogen activator inhibitor-1, and angiotensinogen). ${ }^{1-4,8,15-17}$ Meanwhile, Fox et al showed that inflammatory biomarkers (C-reactive protein, interleukin-6, monocyte chemoattractant protein-1, and soluble intercellular cell adhesion molecule-1) were increased in patients with valvular calcification. ${ }^{18}$ As a result, increased inflammatory mediators from epicardial adipose tissue might have an important role in pathogenesis of MAC and atherosclerosis. As also mentioned before MAC is strongly associated with the pathogenesis of atherosclerosis due to sharing same risk factor.

On the other hand, epicardial fat also produces anti-inflammatory, antiatherogenic adipokines, such as adiponectin and adrenomedullin. ${ }^{19}$ However, Iacebolis et al. showed that adiponectin expression is significantly lower 
in epicardial fat isolated from patients with CAD. ${ }^{19} \mathrm{Nev}$ ertheless, what can influence this equilibrium between harmful and possible protective effects is still unknown. Due to its anatomic proximity to the heart and the absence of fascial bo"undaries, epicardial adipose tissue may interact locally and modulate the coronary arteries and their supplying cardiac valves through the paracrine or vasocrine secretion of proinflammatory adipokines. ${ }^{16}$ It has been shown that epicardial adipose tissue is related to cardiovascular risk factors and coronary artery calcification. ${ }^{20,21}$ In a recent study, Parisi et al reported a significant association between EFT measured by echocardiography and aortic stenosis. ${ }^{22}$ In a more recent study, Alnabelsi et al. showed a correlation between EFT thickness measured by computerize tomography and calcium deposits on mitral annulus and aortic valve. ${ }^{23}$ In our study, we found that EFT was significantly higher in patients with MAC than in control subjects and EFT was positively correlated with presence of MAC. There was no statistically significant difference in CAD incidence between patients with MAC and controls. We think that increased EFT has an important role in pathogenesis of MAC. EFT and MAC share the similar clinical risk factors for cardiovascular diseases, including age, obesity, hypertension, hyperlipidemia, diabetes mellitus and metabolic syndrome. ${ }^{1,24}$ In our study there was no significant difference between patients with MAC and controls with respect to cardiovascular risk factors as shown in Table 1. EFT was significantly higher in patients with MAC than controls independent of these cardiovascular risk factors. Other mechanism might also play in role in this association.

There are several limitations of the present study. First, the number of patients was small. Second, our study had a cross-sectional design, and therefore we could not establish a cause-and-effect relationship between EFT and MAC. Third, echocardiographic EFT measurements might not exactly reflect the amount of total EFT. However, previous studies reported that echocardiographic EFT measurements are well correlated with the total volume of epicardial adipose tissue detected with other radiologic methods. ${ }^{25,26}$ Moreover, echocardiographic assessment of epicardial fat tissue would certainly be less expensive than computerized tomography and echocardiography is routinely performed in high-risk cardiac patients. Because of that, this objective non-invasive measure may be readily available with no extra cost.

\section{Conclusion}

Our findings suggest that echocardiographic EFT measurement could provide additional information on assessing cardiovascular risk. Individuals with increased EFT should receive more attention to reduce unfavorable cardiovascular risk factors and the development of future cardiovascular events.

\section{Declaration of conflicting interests}

The authors declare that they have no conflict of interest

\section{Funding}

The authors received no financial support for the research, authorship and/or publication of this article.

\section{References}

1. Adler Y, Fink N, Spector D, Wiser I, Sagie A. Mitral annulus calcification - a window to diffuse atherosclerosis of the vascular system. Atherosclerosis. 2001;155(1):1-8. Review.

2. Atar S, Jeon DS, Siegel RJ. Mitral annular calcifications: a marker of severe coronary artery disease in patients under 65 years old. Heart. 2003;89:161-164. PubMed.

3. Fox CS, Parise H, Vasan RS, Levy D, O’Donell CJ, D'Agostino RB et al. Mitral annular calcification is a predictor for incident atrial fibrillation. Atherosclerosis. 2004;173:291-294. PubMed.

4. Kizer JR, Wiebers DO, Whisnant JP, Galloway JM, Welty TK, Lee ET et al. Mitral annular calcification, aortic valve sclerosis, and incident stroke in adults free of clinical cardiovascular disease: The Strong Heart Study. Stroke. 2005;36:2533-2537.

5. Fox CS, Vasan RS, Parise H, Levy D, O'Donnell CJ, D’Agostino RB et al. Mitral annular calcification predicts cardiovascular morbidity and mortality: The Framingham Heart Study. Circulation. 2003;107:1492-1496. PubMed.

6. Iacobellis G, Malavazos AE, Corsi MM. Epicardial fat: from the biomolecular aspects to the clinical practice. Int J Biochem Cell Biol. 2011;43(12):1651-1654.

7. Sengul C, Ozveren O. Epicardial adipose tissue: a review of physiology, pathophysiology, and clinical applications. Anadolu Kardiyol Derg. 2013;13(3):261-265.

8. Iacobellis G, Willens HJ. Echocardiographic epicardial fat: a review of research and clinical applications. $\mathrm{J} \mathrm{Am}$ Soc Echocardiogr. 2009;22(12):1311-1319

9. Wang CP, Hsu HL, Hung WC, Yu TH, Chen YH, Chiu 
CA et al. Increased epicardial adipose tissue volume in type 2 diabetes mellitus and association with metabolic syndrome and severity of coronary atherosclerosis. Clin Endocrinol. 2009;70:876-882. PubMed.

10. Sahn DJ, DeMaria A, Kisslo J, Weyman A. Recommendations regarding quantitation in M-mode echocardiography: results of a survey of echocardiographic measurements. Circulation. 1978;58(6):1072-1083. PubMed.

11. Kohsaka S, Jin Z, Rundek T, Boden-Albala B, Homma $\mathrm{S}$, Sacco RL et al. Impact of mitral annular calcification on cardiovascular events in a multiethnic community: the Northern Manhattan Study. JACC Cardiovasc Imaging. 2008;1(5):617-623.

12. Abramowitz Y, Jilaihawi H, Chakravarty T, Mack MJ, Makkar RR. Mitral Annulus Calcification. J Am Coll Cardiol. 2015;66(17):1934-41. PubMed.

13. Lim S, Meigs JB. Ectopic fat and cardiometabolic and vascular risk. Int J Cardiol. 2013;169(3):166-176. PubMed. 14. Iacobellis G, Ribaudo MC, Assael F, Vecci E, Tiberti C, Zappaterreno A et al. Echocardiographic epicardial adipose tissue is related to anthropometric and clinical parameters of metabolic syndrome: A new indicator of cardiovascular risk. J Clin Endocrinol Metab. 2003;88:51635168 .

15. Baker AR, Silva NF, Quinn DW, Harte AL, Pagano D, Bonser RS et al. Human epicardial adipose tissue expresses a pathogenic profile of adipocytokines in patients with cardiovascular disease. Cardiovasc Diabetol. 2006;5: 1.

16. Iacobellis G, Corradi D, Sharma AM. Epicardial adipose tissue: anatomic, biomolecular and clinical relationships with the heart. Nat Clin Pract Cardiovasc Med. 2005;2: 536-543.

17. Cheng KH, Chu CS, Lee KT, Lin TH, Hsieh CC, Chiu CC et al. Adipocytokines and proinflammatory mediators from abdominal and epicardial adipose tissue in patients with coronary artery disease. Int J Obes (Lond). 2008;32:268-274. PubMed.

18. Fox CS, Guo CY, Larson MG, Vasan RS, Parise H, O'Donnell CJ et al. Relations of inflammation and nov- el risk factors to valvular calcification. Am J Cardiol. 2006;97(10):1502-1505. PubMed.

19. Iacobellis G, Pistilli D, Gucciardo M, Leonetti F, Miraldi $F$, Brancaccio $G$ et al. Adiponectin expression in human epicardial adipose tissue in vivo is lower in patients with coronary artery disease. Cytokine. 2005;29:251-255. PubMed.

20. de Vos AM, Prokop M, Roos CJ, MeijsMF, van der Schouw YT, Rutten A. Peri-coronary epicardial adipose tissue is related to cardiovascular risk factors and coronary artery calcification in post-menopausal women. Eur Heart J. 2007;29:777-783. PubMed.

21. Kim BJ, Kim BS, Kang JH. Echocardiographic epicardial fat thickness is associated with coronary artery calcification - results from the CAESAR study. Circ J. 2015;79(4):818-824. PubMed.

22. Parisi V, Rengo G, Pagano G, D’Esposito V, Passaretti $F$, Caruso A et al. Epicardial adipose tissue has an increased thickness and is a source of inflammatory mediators in patients with calcific aortic stenosis. Int J Cardiol. 2015;186:167-169. PubMed.

23. Alnabelsi TS, Alhamshari Y, Mulki RH, Codolosa JN, Koshkelashvili N, Goykhman I et al. Relation Between Epicardial Adipose and Aortic Valve and Mitral Annular Calcium Determined by Computed Tomography in SubjectsAged $\geq 65$ Years. Am J Cardiol. 2016;118(7):1088-93. PubMed.

24. Boon A, Cheriex E, Lodder J, Kessels F. Cardiac valve calcification: characteristics of patients with calcification of the mitral annulus or aortic valve. Heart. 1997;78:472474.

25. Fluchter S, Haghi D, Dinter D, Heberlein W, Kühl HP, Neff W et al. Volumetric assessment of epicardial adipose tissue with cardiovascular magnetic resonance imaging. Obesity (Silver Spring). 2007;15:870-878. PubMed. 26. Hwang JW, Choi UJ, Ahn SG, Lim HS, Kang SJ, Choi BJ et al. Echocardiographic plains reflecting total amount of epicardial adipose tissue as risk factor of coronary artery disease. J Cardiovasc Ultrasound. 2008;16:17- 22. PubMed. 